\title{
A Case of Multiple Myeloma and Renal Failure in a Young Patient
}

\author{
Muftah Othman ${ }^{*}$, Eiman Homid1', Mohamed Sadek², Ali Rahil², Awad Rashed ${ }^{1}$ \\ ${ }^{1}$ Nephology Unit, Hamad Medical Corporation, Doha, Qatar \\ ${ }^{2}$ Medicine Department, Hamad Medical Corporation, Doha, Qatar \\ Email: *msaiti@yahoo.co.uk
}

How to cite this paper: Othman, M., Homid, E., Sadek, M., Rahil, A. and Rashed, A. (2016) A Case of Multiple Myeloma and Renal Failure in a Young Patient. Open Journal of Nephrology, 6, 138-144. http://dx.doi.org/10.4236/ojneph.2016.64017

Received: November 18, 2016 Accepted: December 13, 2016

Published: December 16, 2016

Copyright $\odot 2016$ by authors and Scientific Research Publishing Inc. This work is licensed under the Creative Commons Attribution International License (CC BY 4.0).

http://creativecommons.org/licenses/by/4.0/

\begin{abstract}
Multiple myeloma is a malignant plasma cell disorder that affects the kidney with various clinical presentations. The most common renal manifestation of multiple myeloma is myeloma cast nephropathy. We are describing a young patient with multiple myeloma presented with back pain, anemia and renal impairment. The renal biopsy showed a myeloma cast nephropathy. She was treated with myeloma chemotherapy, high cut-off hemodialysis and autologous hematopoietic stem cell transplantation with good outcome. We report this rare case of multiple myeloma presented with myeloma cast nephropathy (MCN) in a young patient to describe the evidence of light chain removal strategies including plasmapheresis and high cut-off hemodialysis for the management of myeloma cast nephropathy.
\end{abstract}

\section{Keywords}

Myeloma Cast Nephropathy, Plasmapheresis, and High Cut-Off Hemodialysis

\section{Introduction}

Multiple myeloma (MM) is a malignant plasma cell disorder that represents around $10 \%$ of all hematologic malignancies. Typically it is characterized by:

1) More than $10 \%$ clonal expansion of abnormal plasma cells in the bone marrow,

2) Or serum monoclonal protein (M-spike) more than $3 \mathrm{gm} / \mathrm{dl}$ which could be either the whole immunoglobulin or a fragment of it (heavy or light chain alone),

3) And at least one of the myeloma defining events includes Hypercalcemia, Renal impairment, Anemia or osteolytic Bone lesions [1] [2]. More recently the international myeloma working group revised the definition of multiple myeloma to include also any one of the following: greater than $60 \%$ clonal plasma cells on bone marrow biopsy, involved/univolved serum free light chain ratio $\geq 100$ and more than one focal lesion on 
MRI studies [3].

There are different kidney pathologies with various clinical presentations in multiple myeloma. It is commonly manifested as myeloma cast nephropathy (Myeloma Kidney) in $40 \%$ to $60 \%$, AL amyloidosis in $15 \%$ to $35 \%$, monoclonal immunoglobulin deposition disease (MIDD) in $20 \%$ to $25 \%$ and acute tubular necrosis in $7 \%$ to $9 \%$ of the cases. Less common presentations include: Fanconi syndrome with proximal tubulopathy, membranoproliferative glomerulonephritis with monoclonal deposits, immunotactoid glomerulonephritis, fibrillary glomerulosclerosis and plasma cell infiltration. Multiple myeloma may present with various types of kidney injury including proteinuria, nephrotic syndrome, proximal tubulopathy, acute renal failure and chronic kidney disease [4] [5] [6] [7]. Myeloma cast nephropathy (MCN) is almost always occurring in the setting of high tumor burden (patients with a high serum free light chain above $100 \mathrm{mg} / \mathrm{dl}$ ) [7]. Clinically MCN may present as acute onset of renal failure, end stage kidney disease in $10 \%$ of the cases and greater than $75 \%$ have subnephrotic range proteinuria which is mainly Bence-Jones proteinuria that is often dipstick negative. The freely filtered light chains bind tubular Tamm-Horsfall mucoprotein forming casts that obstruct distal tubules. This is usually precipitated by hypercalcemia, hyperuricemia, NSAIDs, volume depletion, and intravenous contrast administration. We report this case to describe the evidence of light chain removal strategies including plasmapheresis and high cut-off hemodialysis for the management of myeloma cast nephropathy.

\section{Case Report}

We report the case of 31 years old women who present to us with nausea, poor appetite and weight loss. She was found to have serum creatinine of $440 \mu \mathrm{mol} / \mathrm{l}$. Her baseline serum creatinine was $70 \mu \mathrm{mol} / \mathrm{l}$ two years ago. She had back pain but there were no hematuria, joint pain, or skin rashes. On questioning she was treated as osteoporosis when presented initially with back pain and multiple thoracolumbar vertebral collapses two years ago during her pregnancy. She has been on long term celecoxib daily for back pain and teriparatide for osteoporosis for two years.

Her physical examination was unremarkable except for pallor and scoliosis of the back. Laboratory investigations revealed that creatinine $440 \mu \mathrm{mol} / \mathrm{l}, \mathrm{BUN} 17 \mathrm{mmol} / \mathrm{l}$, potassium $5.2 \mathrm{mmol} / \mathrm{l}, \mathrm{HCO}_{3} 16 \mathrm{mmol} / \mathrm{l}$, calcium $2.26 \mathrm{mmol} / \mathrm{l}$, phosphorous $1.1 \mathrm{mmol} / \mathrm{l}$ and parathyroid hormone level $23 \mathrm{pg} / \mathrm{ml}$. She was anaemic with hemoglobin $5.5 \mathrm{gm} / \mathrm{dl}$, WBC $4 \times 10^{3} / \mu \mathrm{l}$, platelets $220 \times 10^{3} / \mu \mathrm{l}$ and ESR $107 \mathrm{~mm} / \mathrm{hr}$. Serum total protein was 57 $\mathrm{gm} / \mathrm{l}$, albumin $43 \mathrm{gm} / \mathrm{l}$, liver enzymes and lipids were normal. Urine protein creatinine ratio was $154 \mathrm{mg} / \mathrm{mmol}$ and she had normal urine microscopic examination. Her C3, C4, and ANA were normal and hepatitis B \& C serology were negative. She had normal sized kidneys on abdominal ultrasound scan.

Her serum protein electrophoresis showed gamma globulin immunoparesis and serum immunofixation detected free light chain kappa. 24 hour urine for Bence Jones proteinuria was positive and showed multiple monoclonal bands of free light chain 
kappa (FLC $\kappa$ ). Free Light Chains (FLC) assay: show marked increase in FLC $\kappa$ and increased kappa/lambda ratio $(\kappa / \lambda$ ratio) as below:

- FLC $\kappa 5022 \mathrm{mg} / \mathrm{l}$ (normal range: 3.3 - 19.4),

- FLC $\lambda 7.8 \mathrm{mg} / \mathrm{l}$ (normal range: 5.71 - 26.3),

- $\kappa / \lambda$ ratio 642 (normal range: $0.26-1.65$ ).

Renal biopsy showed 10 glomeruli with no proliferation or nodular lesions. The tubules showed multiple large hyaline laminated and fractured casts with mild focal tubular atrophy. These casts were weakly positive by Periodic acid-Schiff (PAS) stain. There were diffuse mononuclear inflammatory infiltrates and mild focal tubular atrophy and interstitial fibrosis. A Congo red stain for amyloid was negative and immunofluorescence studies showed no immune complex deposits in the glomeruli (Figure 1).

Bone marrow examination was performed and showed $80 \%$ abnormal plasma cells.

The diagnosis of multiple myeloma stage III B according to Salmon and Durie classification was made with renal impairment due to myeloma cast nephropathy (FLC $\kappa$ ) and severe osteoporosis with multiple osteolytic lesions.

She was initially treated with chemotherapy (Dexamethasone and Bortezomib) and high Cut-Off hemodialysis for 12 sessions. Then she received multiple courses of chemotherapy until bone marrow plasma cells became around 5\%. Subsequently she had autologous hematopoietic stem cell transplantation to treat the primary disease. Currently, she is off hemodialysis with stable serum creatinine at $180 \mu \mathrm{mol} / \mathrm{l}$ and negative FLC $\kappa$ and receiving lenalidomide $5 \mathrm{mg}$ daily for 3 weeks every month.

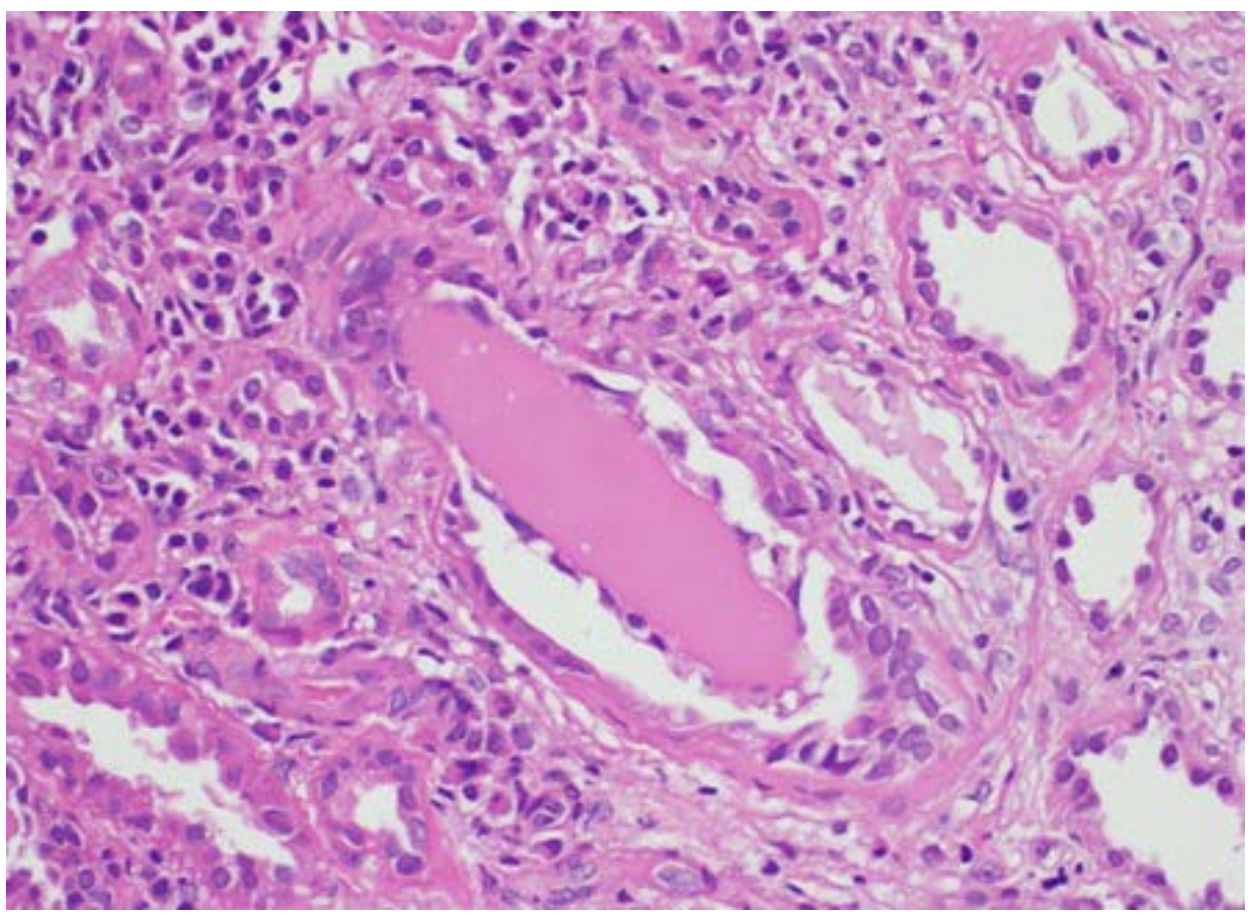

Figure 1. Kidney biopsy showing a large hyaline laminated and fractured casts with mild focal tubular atrophy. These casts were weakly positive by PAS stain. There were diffuse mononuclear inflammatory infiltrates and mild focal tubular atrophy and interstitial fibrosis. 


\section{Discussion}

In our case the diagnosis of multiple myeloma was challenging because of atypical age of onset and atypical presentation with osteoporosis in a young patient. It affects elderly patients with a median age of 66 years at diagnosis and only $2 \%$ of patients are below 40 years of age.

The Incidence of kidney diseases in multiple myeloma varies depending on the definitions of kidney disease used. Up to $40 \%$ of patients will develop renal impairment and $10 \%$ to $15 \%$ will require dialysis [8]. The one-year survival was $80 \%$ in patients with creatinine $<1.5 \mathrm{mg} / \mathrm{dl}$ compared to $50 \%$ in patients with a creatinine $>2.3 \mathrm{mg} / \mathrm{dl}$ [9]. The presence of renal insufficiency is commonly associated with a high tumor burden and the prognosis is poor in patients who required dialysis.

\subsection{Light Chain Removal Strategies for Management of MCN}

These include the use of chemotherapy with plasmapheresis or high cut-off hemodialysis as a means of preserving kidney function.

\subsection{Plasmapheresis (PE)}

In MM, Plasmapheresis (PE) has a theoretical benefit in removing the toxic circulating light chains to spare renal function. There are limited data to support its efficacy because many studies are small, non-randomized, retrospective, and heterogeneous. Three prospective, randomized trials: two of them favor $\mathrm{PE}$, while the most recent study doubt on its use. Therefore, further studies are needed to reveal possible subsets of patients who may be benefited from PE.

The first study in 1988 by Zuchelli et al. randomized 29 patients into two groups. 14 patients received chemotherapy with peritoneal dialysis (control group) and 15 patients received daily PE for 5 days, chemotherapy and hemodialysis only as needed (PE group). In this study renal failure was severe enough to require dialysis in 24 cases, of these, 11 (78\%) cases were in the control group and $13(87 \%)$ cases in the PE group. Only 2 (18\%) patients from the control group compared to 11 (85\%) cases from PE group recovered from dialysis. In this study, plasmapheresis associated with chemotherapy removed large amounts of light chains, improved both renal function and long-term survival [10].

The second study in 1990 was done by Johnson et al. on 21 patients. They compared 10 patients treated with forced diuresis and chemotherapy (control group) and $11 \mathrm{pa}-$ tients treated with plasmapheresis, diuresis and chemotherapy (PE group). Five patients of the control group and 7 patients of the PE group required hemodialysis at presentation; of these, $0 \%(0 / 5)$ patients from the control group compared to $43 \%$ ( 3 out of 7 ) patients from the PE group recovered from dialysis needs on subgroup analysis [11].

In a more recent and larger study by Clark et al., in 2005, who randomized $97 \mathrm{pa}$ tients into two groups: 39 patients in the chemotherapy alone (control group) vs. 58 patients in the plasmapheresis plus chemotherapy (PE group). 14 (36\%) patients in the control group compared to 15 (26\%) patients in the $\mathrm{PE}$ group were requiring hemodia- 
lysis at baseline. Mortality rate at 6 months was 33\% in each group. The composite outcomes at 6 months (death, dialysis dependence or GFR $<30 \mathrm{ml} / \mathrm{min}$ was $69 \%$ vs. $58 \%$ in the control group and PE group respectively. In both groups, dialysis dependence after 6 months was $27 \%$ vs. $13 \%$ and number of patients recovered from dialysis was 7 (47\%) compared to 13 (59\%) in the control group and PE group respectively. This study concluded that there were no significant differences in mortality, composite outcomes and dialysis dependence between the two groups and also plasma exchange was felt to be ineffective [12].

\subsection{High Cut-Off Hemodialysis (HCO-HD)}

Free light chains (FLC) removal by dialysis is another alternative approach and new hemodialysis membranes that remove the circulating light chains have been recently developed. These dialyzers have membranes with very large pore sizes, almost 3 times the size of normal high-flux filters. They allow the passage of molecules up to $45 \mathrm{kDa}$ and through which light chains can pass, but it limits albumin loss. The intravascular compartment contains around $20 \%$ of the total load of FLC. Up to $90 \%$ of FLC can be removed with 3 weeks of extended daily hemodialysis, while PE removes only $25 \%$ of the total amount during the same period [13].

Hutchison et al. in 2009 evaluated the use of chemotherapy and HCO-HD on serum FLC concentrations and recovery of kidney function in 19 patients with MCN and dialysis-dependent acute renal failure [14]. Extended HCO-HD using Gambro HCO 1100 dialyzer and dialysis schedule of eight hours per day for five days, eight hours every other day for the next 12 days, and then six hours three times weekly was followed until the patients became dialysis-independent. Kidney function recovery was defined as dialysis independence 2 weeks after the last dialysis session with estimated GFR more than $10 \mathrm{ml} / \mathrm{min} / 1.73 \mathrm{~m}^{2}$. In the first 6 weeks of treatment, chemotherapy was interrupted in six patients because of infectious complications. The other thirteen patients completed 6 weeks of uninterrupted treatment. There were no significant statistical differences in the amount of dialysis received between the interrupted $(n=6)$ and uninterrupted $(n=13)$ chemotherapy groups. Sustained early reductions in serum FLC concentrations and independence of dialysis were obtained in 13 patients who received uninterrupted chemotherapy and extended HCO-HD. The dialysis independence was achieved at a median of 28 days. The six patients with interrupted chemotherapy did not achieve sustained early FLC reduction. Patients who recovered kidney function had a significantly improved survival and were alive at a median follow up of 360 days, whereas, the interrupted chemotherapy group was associated with significantly worse outcome and median survival of 53 days. The long term benefits of this study were not clear from either intensive dialysis regimen or response to chemotherapy or both [14].

Another study from the same group was done in 67 patients with renal failure due to myeloma cast nephropathy. They received HCO-HD and modern chemotherapy and had their serum FLC level measurement. Around $76 \%$ and $63 \%$ of patients had sustained reductions in serum FLC concentrations and independence of dialysis respec- 
tively. The HD regimen in this study, used Gambro HCO 1100 dialyzers, was almost 8 -hour per session daily for 12 days, then 8 -hour sessions on every other day and finally 6 -hour sessions three time per week after day 21 . Factors which predicted independence of dialysis were the degree of FLC reduction at days 12 and 21 and the time to initiate HCO-HD. This study suggested that the combination of effective chemotherapy and FLC removal is more effective than chemotherapy alone for those patients with severe renal impairment [15].

The use of HCO-HD in MCN is currently evaluated in two randomized controlled trials to determine the beneficial effects of FLC removal in addition to chemotherapy. The European trial of free Light chain removal by extended hemodialysis (EuLITE) study conducted in the UK and it compares conventional high flux HD with HCO-HD in patients receiving chemotherapy on patient outcomes such as independence of dialysis at 3-months. The second randomized controlled phase III trial is conducted in France in patients with multiple myeloma and renal failure related to myeloma cast nephropathy (MYRE). It aims to assess the efficacy of intensive hemodialysis regimen using either a dialyzer with very high permeability to proteins (Theralite TM) or a conventional high-flux dialyzer, while receiving chemotherapy with two different chemotherapy regimens (Bortezomib and Dexamethasone vs Cyclophosphamide + Bortezomib + Dexamethasone).

We will wait for the Eulite and MYRE trials to hopefully illuminate the potential benefit of HCO-HD in patients with myloma cast nephropathy.

\section{Acknowledgements}

The authors wish to thank Dr Imaad Ben Mujeeb, Histopathology Department, Hamad Medical Corporation for his assistance in revising the histopathology slides and supplying the picture.

\section{References}

[1] Kyle, R.A. and Rajkumar, S.V. (2004) Multiple Myeloma. The New England Journal of Medicine, 351, 1860-1873. https://doi.org/10.1056/NEJMra041875

[2] Landgren, O., Kyle, R.A. and Rajkumar, S.V. (2011) From Myeloma Precursor Disease to Multiple Myeloma: New Diagnostic Concepts and Opportunities for Early Intervention. Clinical Cancer Research, 17, 1243-1252. https://doi.org/10.1158/1078-0432.CCR-10-1822

[3] Rajkumar, S.V., Dimopoulos, M.A., Palumbo, A., et al. (2014) International Myeloma Working Group Updated Criteria for the Diagnosis of Multiple Myeloma. The Lancet Oncology, 15, e538. https://doi.org/10.1016/S1470-2045(14)70442-5

[4] Montseny, J.J., Kleinknecht, D., Meyrier, A., et al. (1998) Long-Term Outcome According to Renal Histological Lesions in 118 Patients with Monoclonal Gammopathies. Nephrol Dial Transplant, 13, 1438-1445. https://doi.org/10.1093/ndt/13.6.1438

[5] Nasr, S.H., Valeri, A.M., Sethi, S., et al. (2012) Clinicopathologic Correlations in Multiple Myeloma: A Case Series of 190 Patients with Kidney Biopsies. American Journal of Kidney Diseases, 59, 786-794. https://doi.org/10.1053/j.ajkd.2011.12.028

[6] Korbet, S.M. and Schwartz, M.M. (2006) Multiple myeloma. Journal of the American Soci- 
ety of Nephrology, 17, 2533-2545. https://doi.org/10.1681/ASN.2006020139

[7] Hutchison, C.A., Basnayake, K. and Cockwell, P. (2009) Serum Free Light Chain Assessment in Monoclonal Gammopathy and Kidney Disease. Nature Reviews Nephrology, 5, 621-628. https://doi.org/10.1038/nrneph.2009.151

[8] Dimopoulos, M.A., Terpos, E., Chanan-Khan, A., et al. (2010) Renal Impairment in Patients with Multiple Myeloma: A Consensus Statement on Behalf of the International Myeloma Working Group. Journal of Clinical Oncology, 28, 4976-4984. https://doi.org/10.1200/JCO.2010.30.8791

[9] Winearls, C.G. (1995) Acute Myeloma Kidney. Kidney International, 48, 1347-1361. https://doi.org/10.1038/ki.1995.421

[10] Zucchelli, P., Pasquali, S., Cagnoli, L. and Ferrari, G. (1988) Controlled Plasma Exchange Trial in Acute Renal Failure due to Multiple Myeloma. Kidney International, 33, 1175-1180. https://doi.org/10.1038/ki.1988.127

[11] Johnson, W.J., Kyle, R.A., Pineda, A.A., O’Brien, P.C. and Holley, K.E. (1990) Treatment of Renal Failure Associated with Multiple Myeloma. Plasmapheresis, Hemodialysis, and Chemotherapy. Archives of Internal Medicine, 150, 863-869. https://doi.org/10.1001/archinte.1990.00390160111022

[12] Clark, W.F., Stewart, A.K., Rock, G.A., et al. (2005) Plasma Exchange When Myeloma Presents as Acute Renal Failure: A Randomized, Controlled Trial. Annals of Internal Medicine, 143, 777-784. https://doi.org/10.7326/0003-4819-143-11-200512060-00005

[13] Hutchison, C.A., Cockwell, P., Reid, S., et al. (2007) Efficient Removal of Immunoglobulin Free Light Chains by Hemodialysis for Multiple Myeloma: In Vitro and in Vivo Studies. Journal of the American Society of Nephrology, 18, 886-895. https://doi.org/10.1681/ASN.2006080821

[14] Hutchison, C.A., Bradwell, A.R., Cook, M., et al. (2009) Treatment of Acute Renal Failure Secondary to Multiple Myeloma with Chemotherapy and Extended High Cut-Off Hemodialysis. Clinical Journal of the American Society of Nephrology, 4, 745-754. https://doi.org/10.2215/CJN.04590908

[15] Hutchison, C.A., Heyne, N., Airia, P., et al. (2012) Immunoglobulin Free Light Chain Levels and Recovery from Myeloma Kidney on Treatment with Chemotherapy and High Cut-Off Haemodialysis. Nephrology Dialysis Transplantation, 27, 3823-3828.

https://doi.org/10.1093/ndt/gfr773 
Submit or recommend next manuscript to SCIRP and we will provide best service for you:

Accepting pre-submission inquiries through Email, Facebook, LinkedIn, Twitter, etc. A wide selection of journals (inclusive of 9 subjects, more than 200 journals)

Providing 24-hour high-quality service

User-friendly online submission system

Fair and swift peer-review system

Efficient typesetting and proofreading procedure

Display of the result of downloads and visits, as well as the number of cited articles

Maximum dissemination of your research work

Submit your manuscript at: http://papersubmission.scirp.org/

Or contact ojneph@scirp.org 